\title{
Retrospective review of 208 proved cases of anastomotic ulcer
}

\author{
JOHN R. CONDON ${ }^{1}$ AND NORMAN C. TANNER \\ From St. James's Hospital, London
}

\begin{abstract}
Anastomotic ulceration following the surgical treatment of duodenal and gastric ulcers is more dangerous and troublesome and often more difficult to diagnose than the original lesion. Even in experienced hands it is more difficult to treat successfully both medically and surgically than either duodenal or gastric ulcer. Difficulties in diagnosis, the incidence of complications, and the problems of management have been assessed in 208 proved cases. Current surgical treatment is reviewed.
\end{abstract}

\section{MATERIAL}

The material consists of 208 patients (184 males and 24 females) admitted to St. James's Hospital, Balham, between 1 September 1946 and 1 January 1961. The diagnosis was verified at laparotomy in 198 cases and by positive radiological and/or gastroscopic findings in 10 patients. Patients suspected of having anastomotic ulcer but in whom investigations were negative and patients with recurrent gastric and duodenal ulcers at a distance from the anastomosis were excluded from the series.

All cases were secondary to surgical procedures for duodenal ulcers with the exception of five patients in whom gastrectomy had been performed for gastric ulcer. Four of these five patients had had Billroth type I gastrectomies. The fifth had had a Polya type gastrectomy for pyloric ulcer. Only one other example of anastomotic ulcer was found in over 1,000 patients on whom Polya type gastrectomies for gastric ulcers had been performed at St. James's Hospital.

\section{RESULTS}

Table I indicates the type of operation first performed for peptic ulcer and operative procedures subsequently carried out to deal with anastomotic ulceration.

After partial gastrectomy $83 \%$ of cases developed

${ }^{1}$ Present address: Westminster Hospital, London. symptoms of anastomotic ulcer within three years; the longest period recorded was 10 years, the average 1.7 years. In contrast, after gastroenterostomy the interval before the development of anastomotic ulcer symptoms varied considerably and was randomly distributed from a few days to 39 years, averaging 5.9 years. Anastomotic ulcer dyspepsia was usually but not invariably related to food and relieved by alkalies; nocturnal pain occurred in approximately $30 \%$ of cases but pain was completely absent in seven cases presenting with haemorrhage. After Polya type gastrectomy pain was most commonly felt to the left of the scar and sometimes involved the left chest, axilla, and shoulder. After gastroenterostomy and Billroth I gastrectomy pain was most commonly felt in the region of the epigastrium and tended to remain localized.

Anastomotic ulcer when compared with the original peptic ulcer showed more severe and persistent symptoms and a lessened tendency to heal spontaneously or with medical treatment. Whether suffering from the original peptic or subsequent anastomotic ulcer $72 \%$ of patients presented at hospital on every occasion with the same clinical picture, which in $43 \%$ of cases was intractable pain, in $24 \%$ gastrointestinal haemorrhage, and in $5 \%$ perforated ulcer. One man presented with haematemesis on seven separate occasions while another had had five perforations. The shorter the interval between the first gastric operation and the development of anastomotic ulcer symptoms, the higher the incidence of complications.

Table II gives details of complications arising from the original peptic and subsequent anastomotic ulcers. Complications of both peptic and anastomotic ulcers were approximately equal in number, but judging by the duration of symptoms the former had been present almost three times as long as the latter.

There were only two patients with gastrojejunal colic fistula; one complained of the presence of food in his stools, the other presented with faecal vomiting. Such a low incidence of gastrojejunal colic fistula was due to the routine use of anterior juxtapyloric 
TABLE I

\begin{tabular}{|c|c|c|c|c|c|}
\hline First Operation for Peptic Ulcer & $\begin{array}{c}\text { No. of } \\
\text { Cases }\end{array}$ & $\begin{array}{l}\text { First Operation for } \\
\text { Anastomotic Ulcer }\end{array}$ & $\begin{array}{c}\text { No. of } \\
\text { Cases }\end{array}$ & $\begin{array}{l}\text { Second Operation for } \\
\text { Anastomotic Ulcer }\end{array}$ & $\begin{array}{l}\text { No. of } \\
\text { Cases }\end{array}$ \\
\hline \multirow[t]{3}{*}{ Gastrojejunostomy } & \multirow[t]{2}{*}{112} & Vagotomy & 6 & Nil & $\mathbf{0}$ \\
\hline & & Billroth I partial gastrectomy & 6 & $\begin{array}{l}\text { Billroth II gastrectomy and total } \\
\text { vagotomy }\end{array}$ & 1 \\
\hline & \multirow{2}{*}{9} & Billroth II & 4 & Total vagotomy & 2 \\
\hline & & $\begin{array}{l}\text { Billroth II combined with } \\
\text { vagotomy }\end{array}$ & 2 & Nil & \\
\hline Polya type & & Total vagotomy & 60 & Nil & $\mathbf{0}$ \\
\hline $\begin{array}{l}\text { partial } \\
\text { gastrectc }\end{array}$ & 80 & $\begin{array}{l}\text { Higher gastric resection and } \\
\text { vagotomy }\end{array}$ & 17 & Total gastrectomy & 1 \\
\hline Vagotomy and gastrojejunostomy & 7 & Billroth II & 7 & Nil & 0 \\
\hline
\end{tabular}

TABLE II

COMPLICATIONS OF PEPTIC AND ANASTOMOTIC ULCERATION

\begin{tabular}{lcc} 
Complication & $\begin{array}{l}\text { No. of Complications } \\
\text { in 208 Patients with } \\
\text { Peptic Ulcer }\end{array}$ & $\begin{array}{l}\text { No. of Complications } \\
\text { in Same 208 Patients } \\
\text { with Subsequent } \\
\text { Anastomotic Ulcer }\end{array}$ \\
\hline $\begin{array}{l}\text { Haemorrhage } \\
\begin{array}{l}\text { Perforation } \\
\text { Carcinoma of gastric } \\
\text { remnant after }\end{array}\end{array}$ & 56 & 80 \\
gastrectomy & 44 & 17 \\
$\begin{array}{l}\text { Gastrojejunal colic } \\
\text { fistula }\end{array}$ & - & \\
Stenosis & - & 1 \\
Total number & 104 & 2 \\
\end{tabular}

gastrojejunostomy whenever gastrojejunostomy was considered the procedure of choice. One advantage of the anterior stoma is that it eliminates gastrocolic fistula.

\section{DIAGNOSIS}

A definite diagnosis of anastomotic ulcer was made by combined radiographic and gastroscopic examination in 93 of 137 cases examined. Results were equivocal in 19 patients and negative in 25 cases. Radiology and gastroscopy proved almost equally effective in detecting anastomotic ulcer, but negative findings at gastroscopy were often accompanied by positive findings at barium meal examination and vice versa.

\section{OPERATIVE TREATMENT}

In only one instance was a definite ulcerogenic factor identified, a non-beta cell tumour of the pancreas.

For anastomotic ulceration following gastroenterostomy, two-thirds to three-quarters gastrectomy followed by gastrojejunal anastomosis (Billroth II) was performed in most cases. In only a few cases was vagotomy performed (Table I).

Anastomotic ulceration after Billroth I gastrectomy was treated by dismantling and higher resection with the construction of a gastrojejunal stoma in four cases; vagotomy alone was performed on three functionally satisfactory cases and both procedures were used in the other patients in this group. If a history of massive bleeding was obtained or if obstruction or a wide or deep ulcer was present, conversion to gastrojejunal anastomosis was carried out.

After Polya type gastrectomy the choice lies between a higher gastrectomy or vagotomy alone or the operations combined. Most cases were treated with complete vagotomy and in patients with a deep ulcer, stomal obstruction, or recent bleeding, simple excision of the ulcer or stomoplasty was added. In one case with a recurrent anastomotic ulcer following apparently adequate vagotomy and gastrectomy, a total gastrectomy was required.

\section{RESULTS}

Seventy of the 198 patients operated on were emergency cases. Fifty-six of these acute emergency cases were operated on because of gastrointestinal bleeding and 14 because of perforated anastomotic ulcer. There were nine deaths in the whole series, an overall incidence of $4.5 \%$. Three deaths occurred in patients admitted as emergencies, and six in those admitted routinely; three from the latter group were over 70 years of age.

Results of surgical treatment of stomal ulceration are shown in Table III.

\section{DISCUSSION}

Definite preoperative diagnosis of anastomotic ulcer is often difficult and any ulcer-like pain, periodic dyspepsia, haematemesis, or persistently positive occult blood after gastric surgery should be regarded as due to recurrent ulceration until proved otherwise. Although combined radiographic and gastroscopic 
TABLE III

RESULTS OF FIRST OPERATION FOR ANASTOMOTIC ULCER IN 187 CASES FOLLOWED UP

Complications Found on Follow-up for Five to 20 Years

Completely symptomless

Complete absence of ulcer symptoms,

occasional sweating or flushing, or nausea

admitted on close questioning

Complete absence of ulcer symptoms,

sweating, faintness, or nausea, in-

sufficient to prevent work but worrying

patients at times or frequently

Intermittent ulcer-like pain

Probable stomal ulcer

Proved recurrent stomal ulcer

194 Cases $^{1}$

122

38

'Four postoperative deaths excluded.

examination gave a positive diagnosis in 93 of 137 cases examined, this was an unduly optimistic figure because patients in whom the condition was suspected but not proved were excluded from the series.

Difficulty in diagnosing anastomotic ulcer on barium meal examination may be due to inflammation obscuring the lesion by approximating the ulcer crater edges, thus preventing entry of barium; superimposition of adherent coils of small bowel obscuring the lesion; crater-like niches commonly produced by operative technique, $e g$, transecting and stitching up the lesser curve as in a 'Hofmeister variant'. Contrast medium may be caught between the transversely transected lesser curvature folds giving the appearance of a filling defect as demonstrated in Fig. 1 which shows a large crater-like appearance following partial gastrectomy.

Distension of the afferent loop is sometimes demonstrated radiographically (Fig. 2) and may be due to stenosing jejunal ulcer in the proximal portion of the efferent loop.

The results of medical treatment of anastomotic ulcer are poor (Balint, Cooper, Price, Pulvertaft, and Swynnerton, 1957) so that if anastomotic ulcer is suspected clinically, even though gastroscopic and radiological investigations are negative, laparotomy is indicated. Unless there are very definite contraindications, surgery should be carried out as soon as possible after the diagnosis is made, the urgency being greater the sooner the recurrent ulcer appears after operation.

At operation the stomach and anastomosis are examined carefully and the situation of the recurrent ulcer is confirmed. The presence of a remnant of pyloric or antral mucosa in the duodenal stump must be excluded and a diligent search for ulcerogenic factors, such as islet cell tumour of the pancreas, is made.

Successful surgical treatment will lead to complete

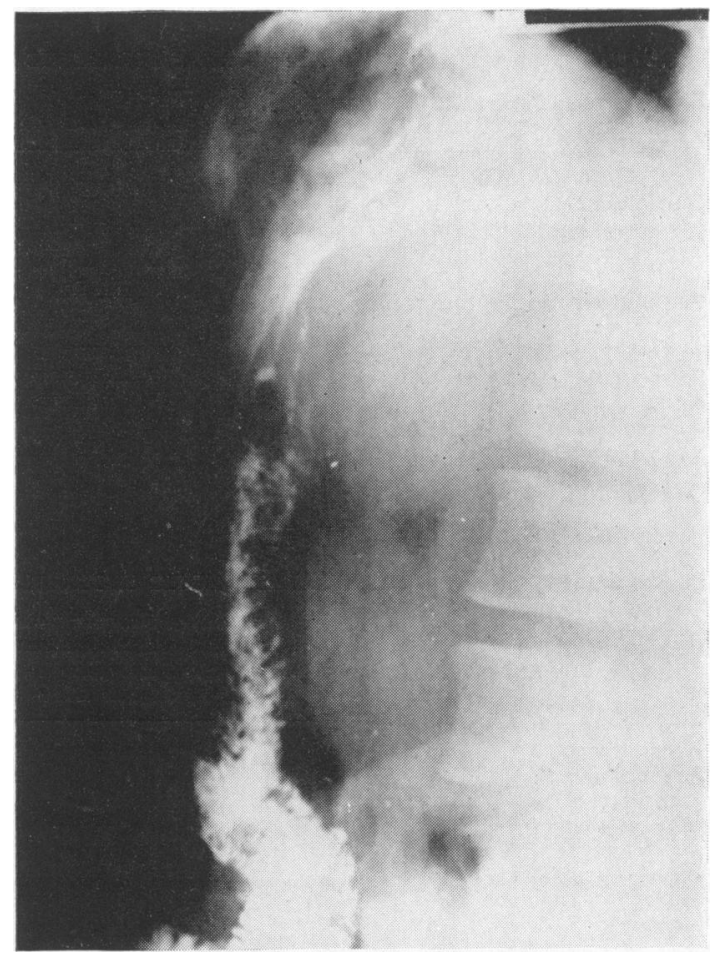

FIG. 1. Crater niche produced by transversely transected lesser curve stomach folds.

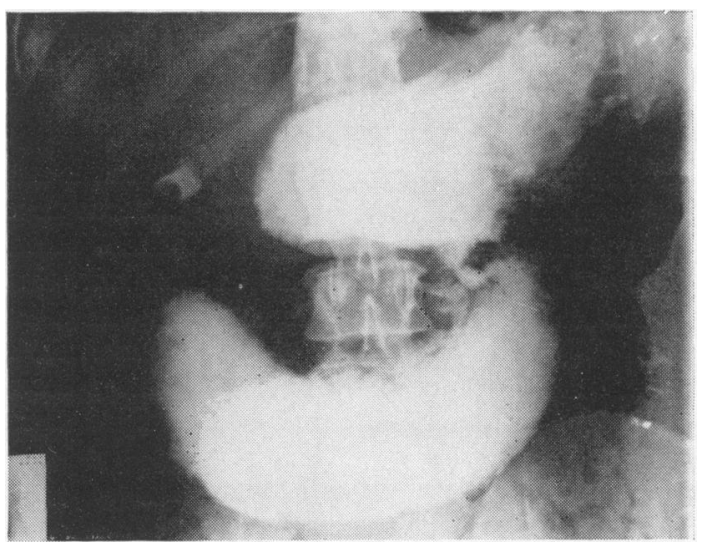

fIG. 2. Dilated afferent loop due to gastrojejunal ulcer following gastroenterostomy.

and lasting remission of symptoms in the vast majority of cases. A very small percentage of patients with persistently recurring anastomotic ulcers after adequate vagotomy and gastrectomy require total 
gastrectomy which should not be delayed once the diagnosis is established.

\section{SUMMARY}

Two hundred and eight proved cases of anastomotic ulcer are reviewed in retrospect.

Symptoms developed on average 1.7 years after gastrectomy and 5.9 years after gastroenterostomy but pain may be completely absent. Complications are more frequent with anastomotic ulcer than with the original peptic ulcer. Radiology and gastroscopy were equally effective in detecting anastomotic ulcer but both were frequently negative.

Surgical treatment is reviewed. Operations were performed in 198 cases, which included 56 with acute gastrointestinal haemorrhage and 14 with perforated anastomotic ulcer. Overall mortality was $4.5 \%$.

\section{REFERENCE}

Balint, J. A., Cooper, G. W., Price, E. C. V., Pulvertaft, C. N., and Swynnerton, B. F. A. (1957). The management of anastomotic ulcer. Lancet, 2, 551-555. 